\title{
Timing disparity of hepatocellular carcinoma (HCC) recurrence in a patient receiving interferon and subsequent direct antiviral agent (DAA) therapy for chronic hepatitis $\mathrm{C}$
}

Christopher Cao, Dina Halegoua-DeMarzio, Robert Coben, Mitchell Conn, Jorge Prieto, Howard Kroop, AnthonyJ. DiMarino and HieWon Hann*

Department of Medicine, Division of Gastroenterology and Hepatology, Thomas Jefferson University Hospital, Philadelphia, PA, USA

\begin{abstract}
The advent of direct acting antiviral (DAA) agents has redefined the treatment landscape for hepatitis $\mathrm{C}$ virus (HCV) within the past decade, with achievement of high $\mathrm{HCV}$ eradication rates.

However, several reports have suggested an increased incidence of tumor recurrence following DAA treatment compared with interferon treatment. In adding to the evolving literature, we herein present a case of a 73-year-old female with long term follow up at our center, who had recurrence of previously treated HCC after 4 years and 7 months on maintenance interferon therapy and subsequent development of a new HCC after 14 months on DAA therapy. Tumor ablation consisted of successful trans-arterial chemoembolization and microwave ablation.
\end{abstract}

\section{Introduction}

Hepatocellular carcinoma (HCC) is a major cause of cancer mortality, of which $50 \%$ is attributable to Hepatitis B virus (HBV) and $25 \%$ is due to Hepatitis $\mathrm{C}$ virus (HCV) [1-4]. The advent of direct acting antivirals (DAA) agents has redefined the treatment landscape for HCV within the past decade, with achievement of high eradication rates in addition to being well tolerated. The introduction of DAA agents has increased the cure rate of $\mathrm{HCV}$ to be above $90 \%$ for most patient groups [5]. The incidence rate of hepatocellular carcinoma (HCC) in the United States, while still rising, has slowed over the past few years [6], correlating with widespread implementation of DAAs.

In the past few years, there has been conflicting data about the dangers of DAAs including the risk for recurrence of HCC. Patients with a concomitant history of HCV cured by DAA and HCC treated by trans-arterial chemoembolization (TACE) or radiofrequency ablation (RFA) have shown a possible increase in the risk for recurrent HCC. These studies have compared the rate of HCC recurrence in patients who have had their HCV treated to untreated control patients [7-9]. Conversely, some studies have suggested that DAA therapies do not appear to increase the risk of liver cancer compared with the interferonbased therapy $[10,11]$. Herein we describe the case of a 73 -year-old female who developed initial HCC and recurrent HCC while on interferon (IFN) treatment and multiple subsequent recurrences of HCC after DAA treatment despite an undetectable HCV viral load.

\section{Case report}

A 73-year-old woman originally presented at age 47 to our Liver Disease Prevention Center in 1996 with chronic HCV. Patient's HCV RNA was 97,000 IU/ml. In 1997, she received amantadine following the initial report documenting amantadine as a treatment for HCV $[12,13]$. Amantadine therapy resulted in decline in HCV RNA after 5 months of therapy. Patient's HCV RNA, however, remained elevated despite repeated amantadine treatments with her HCV RNA reaching $541,000 \mathrm{IU} / \mathrm{ml}$ in 2000 . Patient subsequently participated in a study of combined ursodeoxycholic acid and vitamin $\mathrm{E}$ for two years without success.

After obtaining her medical insurance in 2004, patient was started on IFN (Peg-interferon alpha-2a) and ribavirin at age 55 and achieved successful viral suppression. During the 6-month treatment course, viral remission was achieved but was complicated by subsequent relapse. She underwent a second course of IFN therapy with success but again this was followed by reappearance of HCV (HCV RNA $6.3 \times 10^{\wedge} 6 \mathrm{IU} / \mathrm{mL}$ ). The patient ended up undergoing three courses of therapy with IFN and ribavirin, often at reduced doses due to poor tolerance. At the end of her third course of IFN after achieving an undetectable HCV viral load, for fear of relapse, the decision was made to maintain patient on IFN at a tolerable dose. Patient continued to have an undetectable viral load (HCV RNA $<50 \mathrm{IU} / \mathrm{mL}$ in $2006,<43 \mathrm{IU} / \mathrm{mL}$ in 2009) for the next 4 years and 8 months. In 2005, abdominal CT showed mild nodularity of the liver suggestive of cirrhosis.

In 2010, patient was found to have a $2.8 \mathrm{~cm}$ LIRADS-5 mass in segment 8 on MRI; this was the patient's first diagnosis of HCC. Underlying cirrhosis, with nodularity of the liver on MRI was again noted. At the time, laboratory values were notable for alanine aminotransferase $12 \mathrm{IU} / \mathrm{L}$, alpha fetoprotein $2.3 \mathrm{ng} / \mathrm{mL}$, albumin 4.5 $\mathrm{gm} / \mathrm{mL}$, alkaline phosphatase 72 , total bilirubin $0.5 \mathrm{mg} / \mathrm{mL}$, platelet 146,000/mm3 and HCV RNA < 43 IU/mL. Patient underwent successful

${ }^{\star}$ Correspondence to: Hie-Won Hann, Department of Medicine, Division of Gastroenterology and Hepatology, Thomas Jefferson University Hospital, Philadelphia, PA, USA, Tel: 215-955-5806, E-mail: hie-won.hann@jefferson.edu Key words: interferon treatment, hepatitis C virus, trans-arterial chemoembolization Received: June 15, 2020; Accepted: July 13, 2020; Published: July 16, 2020 
TACE therapy. However, first recurrence of treated HCC with tumor measuring $1.7 \mathrm{x} 1.3 \mathrm{~cm}$ at the previously treated site occurred in 2015 , approximately 4 year and 7 months after initial HCC therapy. Notably patient's viral load was undetectable (HCV RNA $<15 \mathrm{IU} / \mathrm{ml}$ ) on maintenance IFN therapy. Patient underwent repeat TACE for HCC recurrence and was continued on IFN.

With her insurance approval of DAA comprising of ledipasvir/ sofosbuvir, IFN was discontinued and DAA treatment was completed in 3 months. HCC surveillance was continued at 3-month intervals.

In 2016, 14 months after previous TACE and 9 months after completion of DAA treatment, new HCC was discovered in proximity to the previously treated HCC. Liver transplantation was discussed but ultimately refused by the patient. She underwent repeat TACE with repeat imaging showing no more viable tumor. Thereafter patient was closely monitored for HCC recurrence every 3 months including abdominal MRI. Approximately 2 years and 2 months after treatment, patient was found to have a recurrence of HCC when a $5.9 \mathrm{~cm}$ LIRADS- 5 lesion was noted on MRI next to original HCC site. She underwent successful microwave ablation. After 14 months, MRI showed regrowth of the treated areas with tumor invasion into the inferior vena cava, with multiple lung metastasis. Patient's HCV RNA had been undetectable throughout the past 14 years since 2006 (Figure 1).

\section{Discussion and conclusion}

Chronic HCV infection has been global health concern and a major risk factor towards the development of HCC [14]. The risk of developing HCC for a patient with HCV-related cirrhosis has been approximately $2-6 \%$ annually [15]. In the early 2000's despite treatment with IFNbased therapies, HCC burden increased, and HCC survival rates remained low [16]. The advent of DAA therapy for HCV infection has been revolutionary as treatments have shown to be safe and efficacious, with a curative rate with sustained virologic response over 95\% [17]. As implementation of DAAs has become widespread, the number of patients cured of HCV has increased and it has led to a global health sector strategy aiming to eliminate HCV by 2030.

With increasing HCV cure rates, the rate of incident HCC, while still increasing, has slowed. However, there remains a persistent risk of HCC once sustained virologic response (SVR) has been achieved by use of DAA. For the first 12 months after SVR, the absolute rate of HCC has ranged from 1.8-3.5\% [18-20]. Within the first 3.6 years of follow up after achieving SVR, rates of HCC similarly remained high, particularly in patients with cirrhosis [21]. This has led to multiple reports discussing the association of DAA therapy and recurrence of HCC. In 2017 a study by Cabibbo et al. [22] feHCC recurrence rates in DAA HCV treated patients were found to be $12 \%, 26.6 \%$ and $29.1 \%$ at 6-, 12- and 18 months respectively. Additionally, a study by Nagaoki et al. [23] compared HCC occurrence after daclatasvir/asunaprevir treatment in 154 patients with chronic HCV or cirrhosis with HCC occurrence after IFN-based treatment in 244 patients. The study noted that the cumulative HCC incidence at 1,3 and 5 years was respectively $0.6 \%, 9 \%$ and $9 \%$ for the DAA group, and $0.4 \%, 3 \%$ and $5 \%$ for the IFN group $(\mathrm{P}=0.053)$, suggesting a slight increase in HCC incidence in patients who received DAA therapy compared with those who received IFN therapy.

Interestingly, persistent risk for HBV-related HCC has been well documented after SVR of a decade or longer [24-29] and is known to be attributed to an incomplete eradication of the HBV with currently available antiviral treatment [30,31]. Despite complete eradication of HCV with DAA, the pathogenesis of HCC recurrence has not been fully understood and requires more clarification. Currently, it is hypothesized that HCC recurrence in DAA treated patients may be due to the protective mechanism of HCV in HCC recurrence - the inflammatory process of patients with chronic HCV may prevent HCC recurrence as the liver regenerates. As HCV has been cured by DAAs it is possible that previously subclinical cancer lesions may grow without hindrance. Sudden changes prompted by DAAs in chronically inflamed liver of patient might disrupt its anti-tumor response [32]. Furthermore, as HCV is cleared from the body, it is possible that the body's immune response (surveillance) is lessened, allowing tumors to grow more easily. Finally, the presence of DAA-resistant HCV strains must be noted, as presence of active HCV strains may account for a higher HCC incidence rate [33]. Our case seeks to expand to the growing literature suggesting increased HCC recurrence rates in patients with HCV that have been treated with DAA agents compared with IFN treatment. It is unique because of the length of longitudinal care totalling 20 years, in

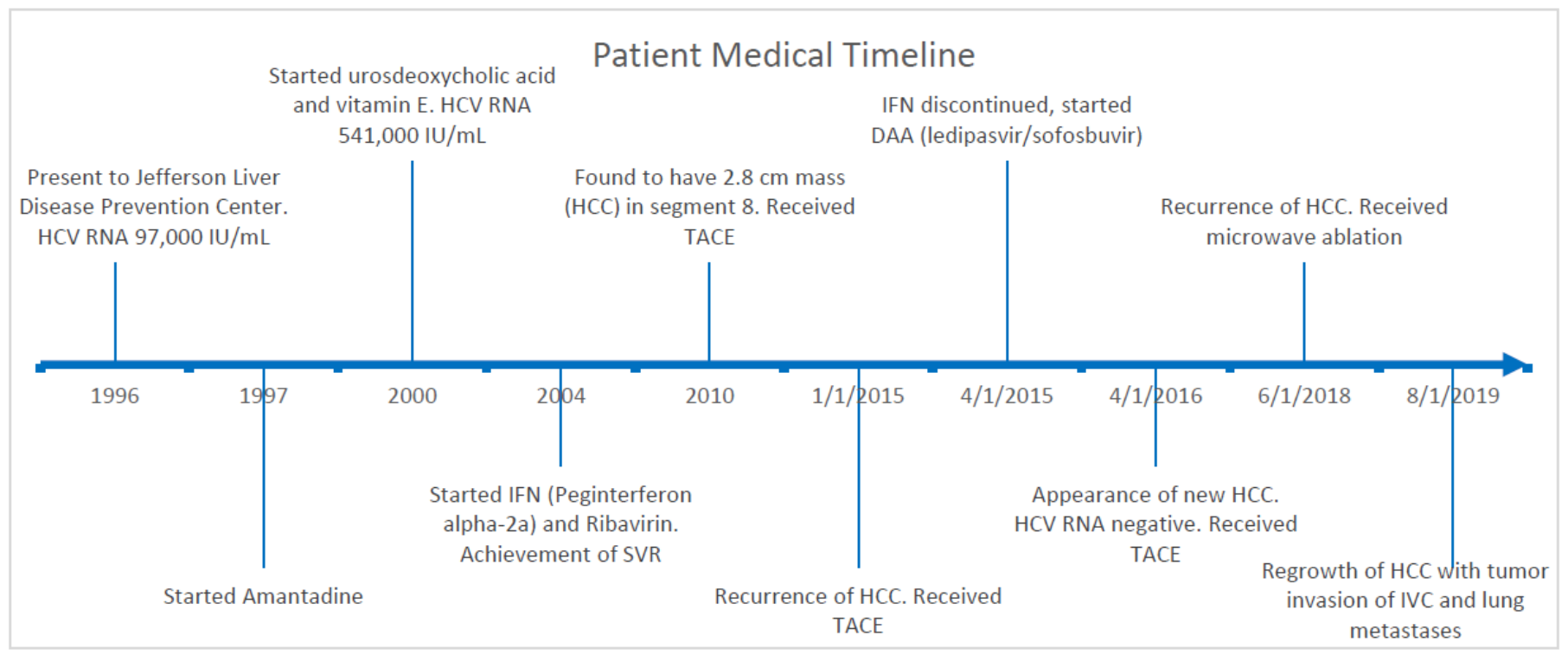

Figure 1. Patient medical timeline 
Christopher C (2020) Timing disparity of hepatocellular carcinoma (HCC) recurrence in a patient receiving interferon and subsequent direct antiviral agent (DAA) therapy for chronic hepatitis $\mathrm{C}$

which HCC recurrence was observed in the same patient while on IFN therapy and on DAA treatment. A comparison may be made for time to HCC recurrence while on IFN versus DAA therapy.

As noted previously, our patient had been treated using IFN with good control of HCV - because the treatment course was 6 months at that time, she underwent 3 individual courses of pegylated interferon (IFN) therapy due to repeated relapses followed by a reduced IFN dose to maintain SVR. Following TACE therapy for her first HCC, patient continued to have HCV viral suppression on maintenance IFN therapy. Patient's first recurrence of HCC was noted 4 years and 7 months after TACE for which patient underwent repeat successful TACE. Patient was eventually transitioned to DAA therapy in 2015 at which time patient did not have viable tumor on MRI examination and had continued viral suppression. The subsequent new HCC occurred 14 months after TACE and 9 months after completion of DAA therapy. Thereafter HCC recurrence was noted within 2 year and 2 months, and 14 months following respective successful tumor ablations. From the time of the first recurrence of HCC after IFN and recurrences after DAA therapy, to the widespread metastasis, our patient had 14 years without detectable HCV viral load.

This case highlights the need for continued surveillance of HCC despite $\mathrm{HCV}$ treatment with viral suppression, as our patient developed HCC at 9 months after completion of DAA therapy and continued having recurrence of HCC for the next 4 years. This observation is in line with prior studies demonstrating continued elevation of HCC risk even after 3.6 years after DAA therapy [21]. Further research is needed in elucidating the pathophysiology for development of HCC in patients with HCV treated with DAA therapy.

\section{References}

1. Perez JF, Armstrong GL, Farrington LA, Hutin YJ, Bell BP (2006) The contributions of hepatitis $\mathrm{B}$ virus and hepatitis $\mathrm{C}$ virus infections to cirrhosis and primary liver cancer worldwide. J Hepatol 45: 529-538. [Crossref]

2. Bray F, Ferlay J, Soerjomataram I, Siegel RL, Torre LA, et al. (2018) Global cancer statistics 2018: GLOBOCAN estimates of incidence and mortality worldwide for 36 cancers in 185 countries. CA Cancer J Clin 68: 394-424. [Crossref]

3. El-Serag HB (2004) Hepatocellular carcinoma: recent trends in the United States. Gastroenterology 127: S27-S34. [Crossref]

4. Lozano R, Naghavi M, Foreman K, Lim S, Shibuya K, et al. (2012) Global and regional mortality from 235 causes of death for 20 age groups in 1990 and 2010: a systematic analysis for the Global Burden of Disease Study 2010. Lancet 380: 20952128. [Crossref]

5. Foster GR, Irving WL, Cheung MC, Walker AJ, Hudson BE, et al. (2016) Impact of direct acting antiviral therapy in patients with chronic hepatitis $\mathrm{C}$ and decompensated cirrhosis. J Hepatol 64: 1224-1231.

6. Kim HS, El-Serag HB (2019) The Epidemiology of Hepatocellular Carcinoma in the USA. Curr Gastroenterol Rep 21: 17. [Crossref]

7. Conti F, Buonfiglioli F, Scuteri A, Crespi C, Bolondi L, et al. (2016) Early occurrence and recurrence of hepatocellular carcinoma in $\mathrm{HCV}$ related cirrhosis treated with direct-acting antivirals. J Hepatol 65: 727-733. [Crossref]

8. Rob B, Moreno C, Van Vlierberghe H, Bourgeois S, Mulkay JP, et al. (2017) The risk of early occurrence and recurrence of hepatocellular carcinoma in hepatitis $\mathrm{C}$ infected patients treated with direct acting antivirals with and without pegylated interferon: a Belgian experience. J Viral Hepat 24: 976-981. [Crossref]

9. Reig M, Mariño Z, Perelló C, Iñarrairaegui M, Ribeiro A, et al. (2016) Unexpected high rate of early tumor recurrence in patients with HCV-related HCC Undergoing interferon-free therapy. J Hepatol 65: 719-726. [Crossref]

10. ANRS collaborative study group on hepatocellular carcinoma (ANRS CO22 HEPATHER, CO12 CirVir and CO23 CUPILT cohorts). Electronic address: stanislas. pol@aphp.fr (2016) Lack of evidence of an effect of direct-acting antivirals on the recurrence of hepatocellular carcinoma: data from three ANRS cohorts. $J$ Hepatol 65: 734-740. [Crossref]
11. Warizy R, Hajarizadeh B, Grebely J, Amin J, Law M, et al. (2017) No evidence for higher risk of hepatocellular carcinoma occurrence or recurrence following directacting antiviral HCV therapy: a systematic review, meta- analyses, and meta-regression. J Hepatol 66: 1204-1212. [Crossref]

12. Smith JP (1997) Treatment of chronic hepatitis C with amantadine. Dig Dis Sci 42 1681-1687. [Crossref]

13. Smith JP, Riley TR, Devenyi A, Bingaman SI, Kunselman A (2004) Amantadine Therapy for Chronic Hepatitis C. A Randomized Double-blind Placebo-controlled Trial. J Gen Int Med 19: 662-668.

14. Koike K, Tsutsumi T, Miyoshi H, Shinzawa S, Shintani Y, et al. (2008) Molecular basis for the synergy between alcohol and hepatitis $\mathrm{C}$ virus in hepatocarcinogenesis. $J$ Gastroenterol Hepatol 23: S87-S91.

15. Sangiovanni A, Del Ninno E, Fasani P, De Fazio C, Ronchi G, et al. (2004) Increased survival of cirrhotic patients with a hepatocellular carcinoma detected during surveillance. Gastroenterology 126: 1005-1014.

16. Alavi M, Janjua NZ, Chong M, Grebely J, Aspinall EJ, et al. (2018) Trends in hepatocellular carcinoma incidence and survival among people with hepatitis $\mathrm{C}$ : An international study. J Viral Hepat 25: 473-481. [Crossref]

17. Falade-Nwulia O, Suarez-Cuervo C, Nelson DR, Fried MW, Segal JB, et al. (2017) Oral direct- acting agent therapy for hepatitis $\mathrm{C}$ virus infection: a systematic review. Ann Intern Med 166: 637-648.

18. Calvaruso V, Cabibbo G, Cacciola I, Petta S, Madonia S, et al. (2018) Incidence of hepatocellular carcinoma in patients with $\mathrm{HCV}$-associated cirrhosis treated with directacting antiviral agents. Gastroenterology 155: 411-421.e414.

19. Innes H, Barclay ST, Hayes PC, Fraser A, Dillon JF, et al. (2017) The risk of hepatocellular carcinoma in cirrhotic patients with hepatitis $\mathrm{C}$ and sustained viral response: role of the treatment regimen. J Hepatol 68: 646-654.

20. Kanwal F, Kramer J, Asch SM, Chayanupatkul M, Cao Y, et al. (2017) Risk of hepatocellular cancer in HCV patients treated with direct-acting antiviral agents. Gastroenterology 153: 996-1005.e1001

21. Kanwal F, Kramer JR, Asch SM, Cao Y, Li L et al. (2020) Long-Term Risk of Hepatocellular Carcinoma in HCV Patients Treated With Direct Acting Antiviral Agents. Hepatology 71: 44-55. [Crossref]

22. Cabibbo G, Petta S, Calvaruso V, Cacciola I, Cannavò MR, et al. (2017) Is early recurrence of hepatocellular carcinoma in HCV cirrhotic patients affected by treatment with direct-acting antivirals? A prospective multicentre study. Aliment Pharmacol Ther 46: 688-695. [Crossref]

23. Nagaoki Y, Imamura M, Aikata H, Daijo K, Teraoka Y, et al. (2017) The risks of hepatocellular carcinoma development after $\mathrm{HCV}$ eradication are similar between patients treated with peg-interferon plus ribavirin and direct-acting antiviral therapy. PLoS One 12: e0182710.

24. Kuzuya T, Katano Y, Kumada T, Toyoda H, Nakano I, et al. (2007) Efficacy of antiviral therapy with lamivudine after initial treatment for hepatitis B virus-related hepatocellular carcinoma. J Gastroenterol Hepatol 22: 1929-1935.

25. Arends P, Sonneveld MJ, Zoutendijk R, Carey I, Brown A, et al. (2015) Entecavi treatment does not eliminate the risk of hepatocellular carcinoma in chronic hepatitis $\mathrm{b}$ : Limited role for risk scores in caucasians. Gut 64: 1289-1295.

26. Yoo J, Hann HW, Coben R, Conn M, DiMarino AJ (2018) Update treatment for HBV infection and persistent risk for hepatocellular carcinoma: Prospect for an HBV cure. Diseases 6: 27 .

27. Shinn BJ, Kistler CCR, Hann HW (2018) Need for HBV cure: Persistent risk fo subsequent new and recurrent hec even after a decade of successful anti-HBV therapy and initial tumor ablation. Arc Cancer Res 6: 1-6.

28. Shinn BJ, Martin A, Coben RM, Conn MI, Prieto J, et al. (2019) Persistent risk for new, subsequent new and recurrent hepatocellular carcinoma despite successful antihepatitis $\mathrm{b}$ virus therapy and tumor ablation: The need for hepatitis $\mathrm{b}$ virus cure. World $J$ Hepatol 11: 65-73. [Crossref]

29. Li N, Lai EC, Shi J, Guo WX, Xue J, et al. (2010) A comparative study of antiviral therapy after resection of hepatocellular carcinoma in the immune-active phase of hepatitis b virus infection. Ann Surg Oncol 17: 179-185.

30. Zeisel MB, Lucifora J, Mason WS, Sureau C, Beck J, et al. (2015) Towards an HBV cure: state-of-the-art and unresolved questions-report of the ANRS workshop on HBV cure. Gut 64: 1314-1326. [Crossref]

31. Levrero M, Testoni B, Zoulim F (2016) HBV cure: Why, how, when? Curr Opin Virol 18: 135-143. [Crossref] 
Christopher C (2020) Timing disparity of hepatocellular carcinoma (HCC) recurrence in a patient receiving interferon and subsequent direct antiviral agent (DAA) therapy for chronic hepatitis $\mathrm{C}$

32. Zanetto A, Shalaby D, Ferrarese A, Becchetti C, Sciarrone S, et al. (2018) Direct-acting antivirals and hepatocellular carcinoma occurrence and recurrence in hepatitis $\mathrm{C}$ virusrelated liver cirrhosis: fact or fiction. Hepatoma Res 4: 70.
33. Sanduzzi-Zamparelli M, Boix L, Leal C, Reig M (2019) Hepatocellular Carcinoma Recurrence in HCV Patients Treated with Direct Antiviral Agents. Viruses 11: 406. [Crossref]

Copyright: (C2020 Christopher C. This is an open-access article distributed under the terms of the Creative Commons Attribution License, which permits unrestricted use, distribution, and reproduction in any medium, provided the original author and source are credited. 